\title{
Bacteriological Profile in Pus Sample of Burn Patients Admitted in Pravara Rural Hospital Loni
}

\author{
Authors \\ Mrs. Sonali Tambe ${ }^{1}$, Dr Rahul Kunkulol ${ }^{*}$, Dr Rashmi Kharde ${ }^{3}$, Mrs Vandana Pulate ${ }^{4}$ \\ ${ }^{1}$ Resident, Department of Pharmacology, ${ }^{2}$ Professor, Department of Pharmacology \\ ${ }^{3}$ Senior Resident, Department of Pharmacology, ${ }^{4}$ Tutor \\ *Corresponding Author \\ Dr Rahul Kunkulol \\ Professor, Department of Pharmacology \\ Email: rahul4420@yahoo.com
}

\section{Introduction}

Burn injuries are a serious health problem in developing countries. They are associated with a significant incidence of death \& disability, multiple surgical procedures, prolong hospitalization $\&$ high cost of health care. ${ }^{1}$

Burn patients are ideal host for opportunistic infections. The development of infection depends on the presence of three conditions, source of organisms, mode of transmission \& susceptibility of the patient. Infection risk for burn patients is different from other patients. Infection remains of foremost concern in the management of burn wounds which is often very difficult to control. ${ }^{3}$ Microbial contamination of burn wound lead to local \& systemic infection. The common pathogens isolated from burn patients include pseudomonas, klebsiella species\& staphylococcus aureus. ${ }^{4}$

Every times antibiotics are used whether appropriately or not in human being, the probability of the development \& spread of antibiotic resistanant bacteria increases. ${ }^{1}$
Keeping all this in mind, it was thought prudent to evaluate the bacterial profile \& antibiotic sensitivity pattern of pus sample in burn patients. This study will help the treating physicians or surgeon to know the most common bacterial growth in pus sample of burn patient $\&$ effective antibiotics on culture report.

Keywords: Monobacterial, Burns patients, Polybacterial, Pseudomonas, Staphylococcus aureus.

\section{Aims \& Objectives}

To study the bacteriological profile in pus sample obtained from burn patients.

\section{Material and Methods}

This was a prospective longitudinal study done in Department of Pharmacology in collaboration with the Department of Microbiology and Department of Burn at Pravara Rural Hospital, Loni during a period between December 2015 to December 2017. Total 250 Patients of burn admitted in the burns ward were enrolled for the 
study and subjected to following inclusion and exclusion criteria

\section{Inclusion Criteria}

1. All patients of any age and either sex admitted with burn and have pus discharge.

2. All pus samples of burn patients sent to microbiology department for culture and sensitivity.

3. Records of all burn patients with pus samples send for culture and sensitivity.

4. Patients ready to give written informed consent for the study.

\section{Exclusion Criteria}

1. Burn patients with no pus discharge.

2. Burn patients not ready to participate in the study.

3. Burn patients with any chronic diseases like diabetes mellitus, AIDS, viral infections, tuberculosis.

4. Patients of burns on chronic anti malignancy/anticancer drugs, antibiotics and corticosteroids.

All the patients' records and culture sensitivity report satisfying above criteria were studied for the following parameters.

Bacteriological Profile of the pus samples were recorded from the reports of burn patients.

\section{Observations}

Table No. 1 Incidence of Monobacterial, Polybacterial and No Growth (Sterile)

\begin{tabular}{|c||c||c|}
\hline Type of growth & No. of pus samples & Percentage \\
\hline \hline Monobacterial & 161 & $\mathbf{6 4 . 4 \%}$ \\
\hline \hline Polybacterial & 49 & $\mathbf{1 9 . 6 \%}$ \\
\hline \hline Sterile & 40 & $\mathbf{1 6 \%}$ \\
\hline
\end{tabular}

Table no. 1: By applying " $Z$ " test of difference between two sample proportions the proportion of Monobacterial incidence is significantly higher than other type of growth $(\mathrm{p}<0.05)$.

Monobacterial growth was seen in $64.4 \%$ of pus samples and Polybacterial in only $19.6 \%$
Figure 1: Incidence of Monobacterial and Polybacterial and no Growth (Sterile)

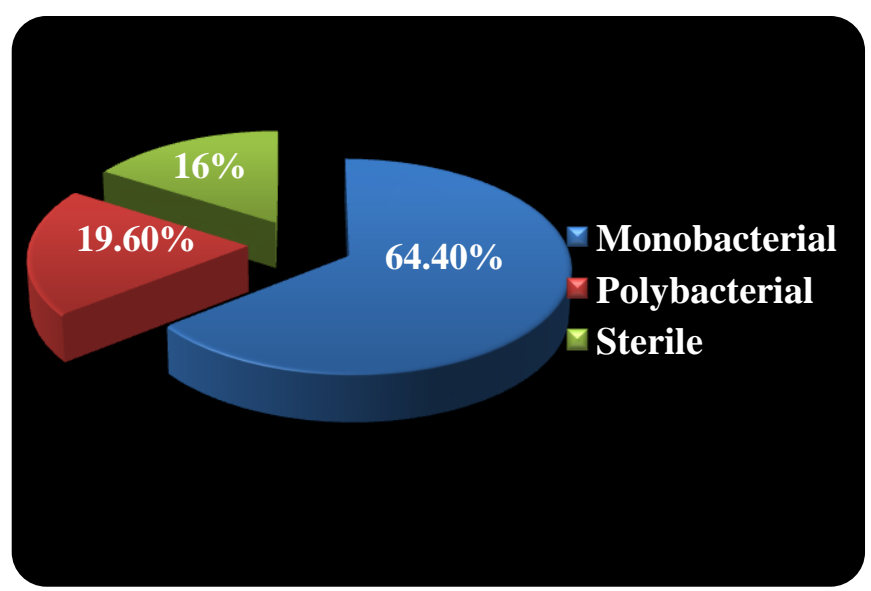

Table No. 2: Culture Reports of Pus Samples

\begin{tabular}{|l||c||c|}
\hline \hline Organism & Number & Percentage \\
\hline \hline Citrobacter & 11 & $4.4 \%$ \\
\hline \hline Pseudomonas & 76 & $\mathbf{3 0 . 4 \%}$ \\
\hline \hline Staphylococcus aureus & 43 & $\mathbf{1 7 . 2 \%}$ \\
\hline \hline Acinetobacter & 9 & $3.6 \%$ \\
\hline \hline Enterococcus species & 4 & $0.4 \%$ \\
\hline Micrococcus species & 2 & $1.6 \%$ \\
\hline \hline E'coli & 12 & $0.8 \%$ \\
\hline \hline Klebsiella & 2 & $0.8 \%$ \\
\hline \hline Diptheroides & 1 & $0.8 \%$ \\
\hline \hline Enterobactor & 7 & $2.8 \%$ \\
\hline \hline Pseudomonas \&Staphylococusaureus & 1 & $0.4 \%$ \\
\hline \hline E'coli\&Klebsiella & 9 & $3.6 \%$ \\
\hline \hline Klebsiella\& Proteus & 13 & $5.2 \%$ \\
\hline \hline Klebsiella\& Pseudomonas & 5 & $2 \%$ \\
\hline \hline Staphylococusaureus\&Klebsiella & 2 & $0.8 \%$ \\
\hline \hline Proteus \& Pseudomonas & 6 & $2.4 \%$ \\
\hline \hline Acinetobacter\& Pseudomonas & 3 & $1.2 \%$ \\
\hline \hline Citrobater\& Pseudomonas & 2 & $0.8 \%$ \\
\hline \hline Citrobater\&Klebsiella & 1 & $0.4 \%$ \\
\hline \hline Citrobater\&Staphylococusaureus & 250 & $16 \%$ \\
\hline \hline Sterile & & \\
\hline \hline Total & $200 \%$ \\
\hline
\end{tabular}

Table no. 2: By applying $\mathrm{Z}$ test of difference between two sample proportions the proportion of Pseudomonas and Staphylococusaureus are significantly higher than other organisms $(\mathrm{p}<0.05)$ . Pseudomonas and Staphylococusaureus were the most common bacterial isolate found in culture of pus samples. 


\section{JMSCR Vol||06||Issue||05||Page 765-769||May}

Figure 2: Culture Reports of Pus Samples Percentage

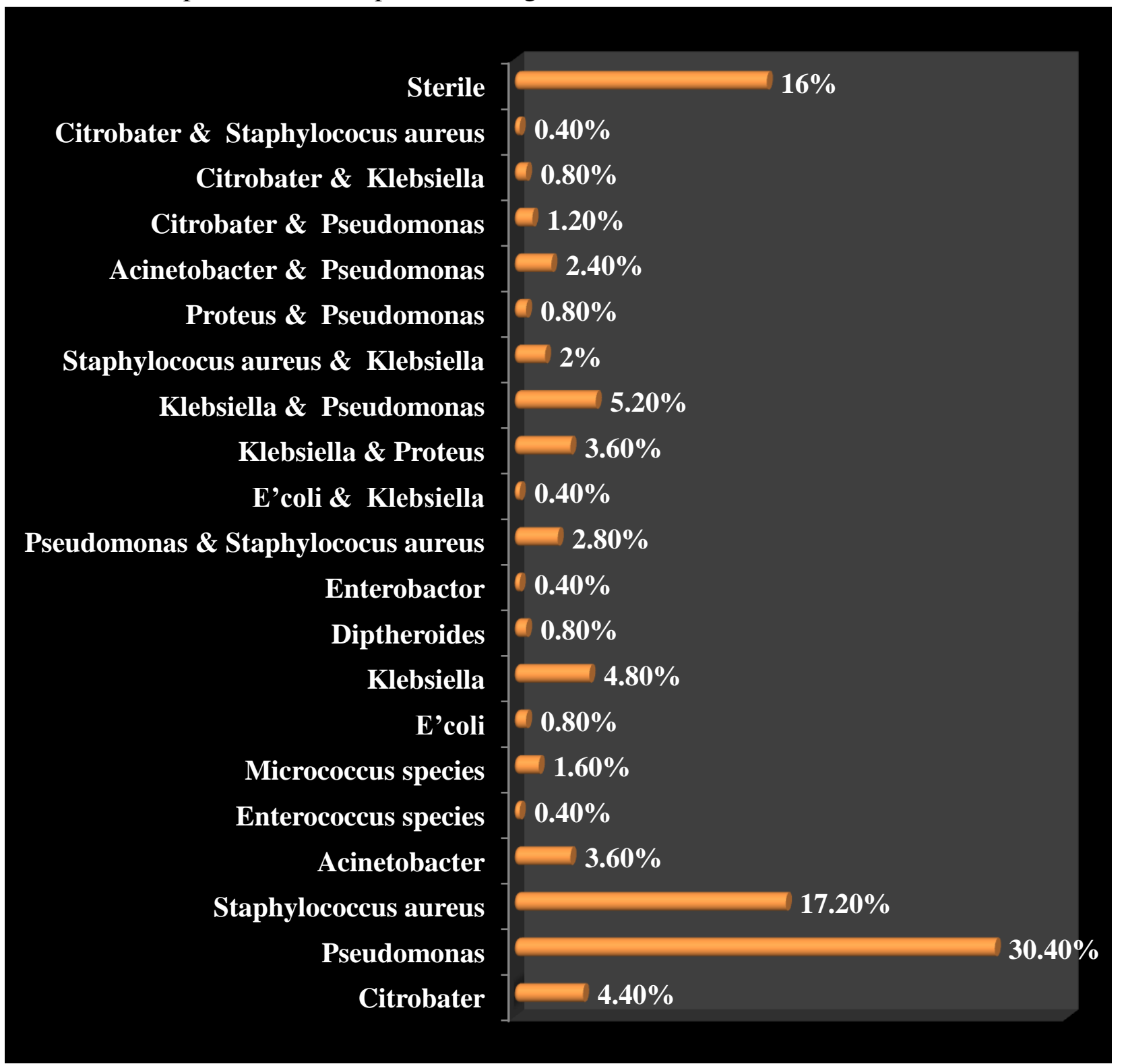

Table No. 3: Overall Incidence of Various Bacteria in the Pus Samples of Burn Patients

\begin{tabular}{|c|c|c|c|c|c|c|}
\hline \multirow{2}{*}{ Bacteria } & \multicolumn{2}{|c|}{ Monobacterial } & \multicolumn{2}{|c|}{ Polybacterial } & \multicolumn{2}{|c|}{ Total } \\
\hline & No. & $\%$ & No. & $\%$ & No. & $\%$ \\
\hline \multicolumn{7}{|l|}{ Gram Positive (21.6\%) } \\
\hline Staphylococcus aureus & 433 & $17.2 \%$ & 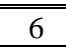 & $2.4 \%$ & 49 & $19.6 \%$ \\
\hline Enterococcus & 1 & $0.4 \%$ & 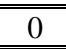 & $0 \%$ & 1 & $0.4 \%$ \\
\hline Micrococcus & 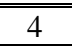 & $1.6 \%$ & 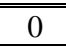 & $0 \%$ & 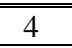 & $1.6 \%$ \\
\hline \multicolumn{7}{|l|}{ Gram Negative (62.4\%) } \\
\hline Pseudomonas & 76 & $30.4 \%$ & 16 & $6.4 \%$ & 92 & $36.8 \%$ \\
\hline Proteus & 0 & $0 \%$ & 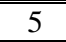 & $2 \%$ & 5 & $2 \%$ \\
\hline Acinetobacter & 9 & $3.6 \%$ & 3 & $1.2 \%$ & 12 & $4.8 \%$ \\
\hline Citrobacter & 11 & $4.4 \%$ & 3 & $1.2 \%$ & 14 & $5.6 \%$ \\
\hline Ecoli & 2 & $0.8 \%$ & 1 & $0.4 \%$ & 3 & $1.2 \%$ \\
\hline Diptheroides & 2 & $0.8 \%$ & 0 & $0 \%$ & 2 & $0.8 \%$ \\
\hline Klebsiella & 12 & $4.8 \%$ & 15 & $6 \%$ & 27 & $10.8 \%$ \\
\hline Enterobacter & 1 & $0.4 \%$ & 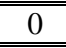 & $0 \%$ & 1 & $0.4 \%$ \\
\hline Sterile & & & & & 40 & $16 \%$ \\
\hline Total & 161 & $64.4 \%$ & 49 & $19.6 \%$ & 250 & $100.00 \%$ \\
\hline
\end{tabular}

Table 3: Gram negative bacteria (62.4\%) were significantly higher than gram positive bacteria (21.6\%) 
Figure 3: Distribution of Gram Positive and Gram Negative Bacteria

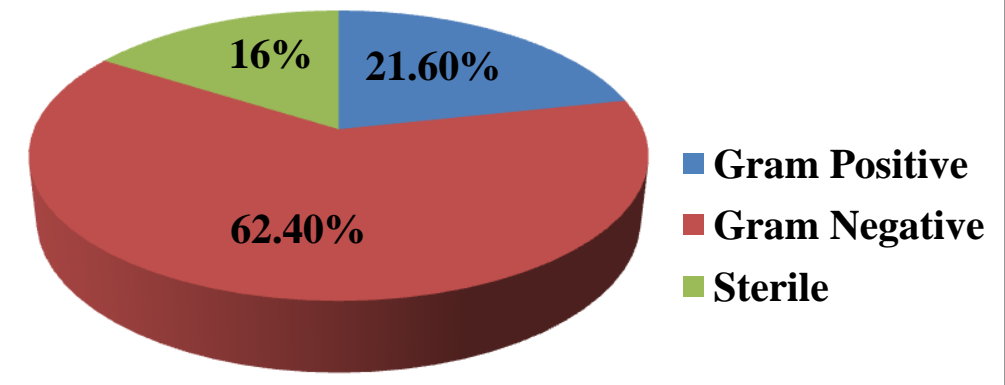

\section{Discussion}

Knowledge of a burn centre microbial flora and the current antibiotic susceptibility pattern of isolates are important for the management of burn patients. ${ }^{5}$ This study was performed to assess the bacteriological profile in burn patients so as to prevent the morbidity and mortality in burn patients.

In the present study 250 pus samples were collected from burn ward. All these pus samples were collected in sterile test tubes, with sterile cotton swabs, under direct illumination and were sent to the Microbiology department for the culture and sensitivity. Out of all the pus samples $64.4 \%$ were monobacterial isolates and $19.6 \%$ were polybacterial responsible for mixed infections.

Altogether, different bacterial species were isolated with Pseudomonas aeruginosa (30.4\%) being the prominent one followed by Staphylococcus aureus (17.2\%) Klebsiella (4.8\%), Citrobacter (4.4\%), Acinetobacter (3.6\%). A study done by Manjula et $\mathrm{al}^{9}$, (2007) shows that most commonly isolated organism was Pseudomonas aeruginosa $(51.5 \%)$ followed by Acinetobacter spp. (14.28\%), S. aureus (11.15\%), Klebsiella spp. (9.23\%) were predominant. Other study done by Ganesamoni S. et $\mathrm{al}^{8}$, (2010) also shows that commonest organism was P.aeruginosa (81.1\%), followed by Acinetobacter spp. and S. aureus.

Among the total 250 bacterial isolates, $62.40 \%$ were gram negative and $21.60 \%$ were gram positive bacteria. In similar study conducted by Yakhaet al. ${ }^{11} \&$ Acharya ${ }^{10}$ Gram negative bacteria were found predominant. Isolation of Gram negative bacteria, during this study was higher, as they are more prevalent aerobes and facultative anaerobes in abscesses and skin wound, these bacteria have well recognized property for abscess formation in open as well as in visceral infection, which increases their incidence in both open and closed types of wound. Isolation of Gram negative bacteria also increases in the cases of Hospital acquired infections (HAIs). A study conducted by Banjara $^{12}$ at TUTH showed the high rate of Gram negative bacteria in HAI.

\section{Conclusion}

The study suggests that the common bacterial isolates in pus samples of burn patients were Pseudomonas Aeruginosa and Staphylococcus Aureus.

\section{References}

1. Alireza Ekrami, Enayat Kalantar, Bacterial infection in burn patients at a burn hospital in Iran.Indian J Med Res 126,December 2007,PP- 541-544

2. Neely AN, Holder IA: Antimicrobial resistance. Burns.1999; 25:17-24

3. Sai KP, Babu M: Traditional medicine and practices in burn care: Need for newer scientific perspectives. Burns 1998; 24: 387-388 
4. Goodman and Gillmans "The Pharmacological Basis of Therapeutics"-Tenth Edition. Page no.1030-1032, 1044-1055

5. Kaur H, Bhat J, Anup R, Anvikars, Gadge V. Bacterial profile of blood and burn wound infections in burn patients. Burns 2006; 34: 89-95.

6. ArtiKapil: the challenge of Antibiotic resistance: need to contemplate Review Article. Indian J Medicine Res-121, February 2005, PP-83-91.

7. Cason JS: Treatment of burns. Published by Chapmann \& Hill

8. Ganesamoni, S., Kate, V., Sadasivan, J.Epidemiology of hospitalized burn patients in a tertiary care hospital in South Indi a.NCBI. 36(3): 422-9.

9. Manjula, M., Priya, D., Varsha, G. 2007. Bacterial isolates from burn wound infections and their antibiograms: A eightyear study. Indian J. Plastic Surgery, 40(1): 25-28.

10. Acharya S (2012) Multi Drug Resistant of bacterial Isolates from wound Infection. M.Sc. dissertation submitted to the Department of Microbiology, Nepal.

11. Yakha JK, Sharma AR, Dohal N, Lekhak B, Banjara MR (2014) Antibiotic Susceptibility Pattern of Bacterial Isolates Causing Wound Infection Amongthe Patients Visiting B \& B Hospital. Nepal Journal of Science and Technology 15(2): 91-96.

12. Banjara MR (2002) Study of Air, Water and Wound Infection in Different Wards of TUTH. M.Sc. dissertation submitted to the Central Department of Microbiology, Nepal. 